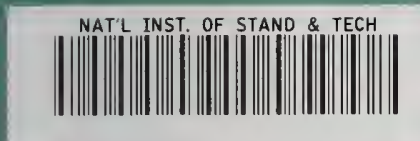

NBSIR $81-2341$

\title{
Chemical Thermodynamic Data Banks
}

U.S. DEPARTMENT OF COMMERCE National Bureau of Standards National Measurement Laboratory Chemical Thermodynamics Division Washington, DC 20234

August 1981

Interim Report

\section{Prepared for}

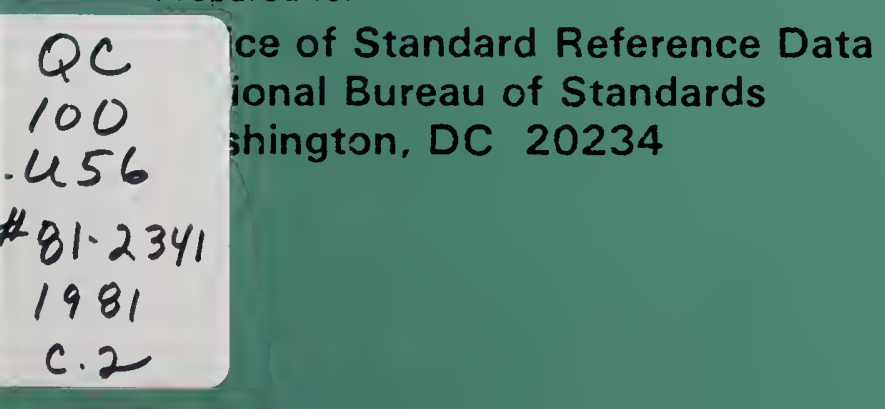





\section{CHEMICAL THERMODYNAMIC DATA BANKS}

David Garvin, Vivian B. Parker and Donald D. Wagman

U.S. DEPARTMENT OF COMMERCE

National Bureau of Standards

National Measurement Laboratory

Chemical Thermodynamics Division

Washington, DC 20234

August 1981

Interim Report

Prepared for

Office of Standard Reference Data

National Bureau of Standards

Washington, DC 20234

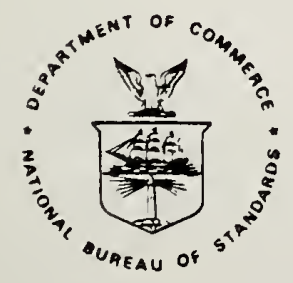

U.S. DEPARTMENT OF COMMERCE, Malcolm Baldrige, Secretary NATIONAL BUREAU OF STANDARDS, Ernest Ambler, Director 



\section{Table of Contents}

1 Introduction

2. Evolution of Data Evaluation in

in Chemical Thermodynamics

3. Description of Data Banks 5

3.1 Information Resources

3.2 Evaluation of Data

3.2.1 The Thermochemical Data System

3.2.2 Treatment of Individual Papers

Page

3.2.3 Values for Chemical Thermodynamic

Properties

4. Thermodynamic Data Banks at the Institute for High Temperatures

5 What of the Future?

References

Figures 

Chemical Thermodynamic Data Banks*

David Garvin, Vivian B. Parker and Donald D. Wagman

National Bureau of Standards

Washington, D.C. 20234

Abstract

A substantial critical evaluation of chemical thermodynamic measurements on inorganic and $C_{1}-C_{2}$ organic compounds has recently been completed. This provides selected values for some 14300 substances, based on a collection of 250,000 measurements. This work is placed in a historical context of three earlier comprehensive evaluations of thermochemical data.

During the course of this work data banks of several types have been developed: bibliography, extracted unevaluated data, evaluated measurements (catalogs of reactions) and selected chemical thermodynamic properties for individual substances. The design, structure and use of those data banks are described.

The course of modern data evaluation, based on these files, is discussed briefly in terms of tests for inter-measurement consistency and automated solutions of large networks of data.

A complementary thermodynamic data system developed at the Institute for High Temperatures, Moscow, USSR is described briefly. Proposed international activities are outlined.

Key words: chemical thermodynamics; data evaluation; data banks; information systems; networks of data; standard reference data; thermochemistry.

*Presented at the American Chemical Society Meeting, Atlanta, GA., March 1981 

1. Introduction

The purpose of this paper is to describe several data banks that have been developed as aids in providing compilations of evaluated chemical thermodynamic data. They are also becoming available to the thermodynamics community as information resources.

The first data resources to be described are those developed at the Chemical Thermodynamics Data Center at the National Bureau of Standards. They have been used primarily for the evaluation of thermochemical data.

Also to be described is a second set of data banks developed primarily for use in the evaluation of thermophysical data. This set of data banks and an associated data management system have been developed at the Institute for High Temperatures of the USSR Academy of Science, Moscow.

These data banks reflect only part of the world wide activity in the evaluation of chemical thermodynamic data. Some other major activities are mentioned very briefly in the final section of this paper. There are also data dissemination and calculation systems that are being developed to simplify retrieval and use of thermodynamic data. This rapidly growing activity is not reviewed here.

To begin with it is advisable to define the terms being used here. "Thermochemical properties" are those that involve chemical reactions and mixing processes such as enthalpies of reaction combustion, solution and dilution; Gibbs energies from equilibrium constants, electromotive cell measurements, and mixing experiments; entropy and heat capacity changes. In all of these chemical and physical (mixing) processes the chemical identity of the substance in the system changes. "Thermophysical properties" are those that pertain to single substances and mixtures that remain essentially unchanged during a process. They include PVT properties, entropy, heat capacity, and enthalpy changes accompanying changes of temperature and pressure, Gibbs energy functions, enthalpies of vaporization and transition, and all other aspects of phase changes. 
These two types of properties are illustrated in figure 1 . The horizontal arrows for reactions apply to changes in thermochemical properties, the vertical arrows to changes in thermophysical properties with temperature.

"Chemical thermodynamic properties" is the name given here to the aggregation of thermochemical and thermophysical properties. It includes all of those properties needed for a study of chemical equilibria and heat effects of reactions as a function of temperature, pressure and composition (of mixtures.)

The data banks developed at NBS are of several types:

- Data extracts of thermodynamic measurements (substance/property index)

- Bulletin of Chemical Thermodynamics

(Inorganic chemistry section)

- Catalogs of evaluated Chemical Thermodynamic Measurements

- Selected Values of Chemical Thermodynamic

Properties (NBS Tech. Note 270)

From our point of view the first three are aids to the preparation of the fourth: "Selected Values." This is a data bank that contains our recommendations on the thermodynamic properties at $25{ }^{\circ} \mathrm{C}$ for inorganic compounds and low molecular weight organics. It has just been completed and is the fourth full-scale evaluation of chemical thermodynamic data with which NBS has been associated in the past fifty five years. The data banks are best considered in the context of this activity.

2. Evolution of Data Evaluation in Chemical Thermodynamics

The nature and scope of thermochemical data evaluation activities have undergone a series of changes in the past 55 years, both in the collection and storage of thermochemical data and in the actual data evaluation process itself. A brief history of this evolution is in order. 
The International Critical Tables under the editorship of E. Washburn at NBS published a set of tables of heats of formation in 1929. These tables [1] were compiled by F. Russell Bichowsky, Naval Research Laboratory, and represented the first modern attempt to collate all the published data involving enthalpies of reaction and to prepare self consistent tables of selected values of enthalpies of formation.

Approximately 3700 inorganic and $C_{1}-C_{2}$ organic compounds were listed, with either an enthalpy of formation, of dilution, or of transition. Also included was the measurement type, by code, and the reference: a shorthand documentation. These 3700 total data items were obtained from a total of 1113 literature references. These references were abstracted, indexed and coded by compound and type of measurement. Bichowsky developed this as a hand written $3 \times 5$ card file. This was the data bank. (Conservatively it must have had close to $120003 \times 5$ cards of pertinent information). The evaluation process itself was a completely manual, sequential approach of making selections, one compound and value at a. time, building relationships and networks until a stable set of values for the enthalpies had been developed.

This manual, sequential approach has dominated thermochemical data evaluation and is still being used. Only during the past decade has the computer based simultaneous solution approach become important. More on this later.

This early data bank was maintained and added to and in 1936 Bichowsky and Rossini [2] published their "Thermochemistry of the Chemical Substances," which updated the enthalpies of formation, reevaluating and reassembling a self-consistent set of best values for approximately 6000 (inorganic and $C_{1}-C_{2}$ organic) substances. Phase transition enthalpies were included. The total number of data items was 6600 . The mesurements used were described tersely and compared in the text. There were now 3750 references. The $3 \times 5$ card data bank had increased to 22000 items. 
By 1940 it was quite obvious that the tables and maintenance of the data files could no longer be a part-time "extracurricular" activity for one individual.

A formal program was undertaken at NBS headed by Frederick D. Rossini. Donald D. Wagman joined the staff in 1940 and William H. Evans in 1947. It was decided taht the scope of teh work must be enlarged, that evaluating only the $\Delta_{r} H^{\prime}$ 's could be both misleading and incomplete, that both the Gibbs energy and entropy should be included. When the volume "Selected Values of Chemical Thermodynamic Properties," NBS Circular 500 [3] was published in 1952, a line entry in Series I, on the formation properties, contained not only $\Delta_{f} H^{\circ}$, but also $\Delta_{f} G^{\circ}, \log K_{f}, S^{\circ}, C_{p}^{\circ}$, and $\Delta_{f} H_{0}^{\circ}$. The phase transition properties (Series II) covered were $\Delta H, T, \Delta S, P, \Delta C_{p}$. The number of data $i$ tems was 15000 based on 8500 references. The card bank expanded to 50000. The tables were documented by reference citations only.

This expansion of the tables meant that the user now had data for the prediction of equilibrium constants and also could correct them to temperatures other than the reference point, $298.15 \mathrm{~K}$.

The expansion also had a major impact on the data evlauation process. Gibbs energy and entropy data could be used to confirm enthalpy measurements and the combined set could be used to predict values for which there was no direct reliable measurement. This meant that data evaluation became more complex and required more decision making.

It is now 1981 and NBS has just completed the fourth major evaluation of chemical thermodynamic data. Originally conceived as a revision of Circular 500, it is a greatly expanded, completely reevaluated self-consistent set of data. It has been issued as NBS Technical Note 270 in eight parts over the past 16 years [4]. A combined volume will be issued later this year. It covers the formation properties of 14,300 substances and has 26,000 data items, half of which are enthalpies of formation. We estimate that 60,000 references were 
used, and that these produced 180,000 cards in our compound/property index. A sample page from the final section of NBS Tech. Note 270 is shown in Figure 2. The documentation for this work has not been published. Our plans are described later in this paper.

The growth and changing scope of compiled chemical thermodynamic data are displayed in Figures 3 and 4.

It became increasingly clear by the later sixties that new methods must be developed to cope with the explosion of the literature and the more complex nature of the evaluation process. We turned to the computer for help in (1) staying on top of the literature (simplify the abstracting of data)

(2) evaluating and intercomparing measurements (3) updating tables, and (4) documenting and disseminating the information. The developments reported in the next section reflect this change of procedure.

3. Description of Data Banks

The NBS data banks mentioned at the beginning of this paper were developed in the course of the evaluation of chemical therodynamic measurements for the NBS tables "Selected Values of Chemical Thermodynamic Properties." The data banks are of two types:

- information resources

- evaluated data

3.1. Information Resources These are of three types: bibliography, microform copies of papers and extracts of data. The last, the "card file" mentioned earlier, is the principal resource. It contains many types of information, all needed for the evaluation of data:

- Experimentally measured enthalpies of reaction, fusion, vaporization, sublimation, transition, solution and dilution. 
- Vapor pressures, solubilities, chemical equilibria and EMF measurements.

- Heat capacities, experimental and statistically calculated entropies.

- Molecular structure and energy level data.

- PVT data and correlations of properties with structure.

A11 of this information is organized by compound and then by the property measured. In order to keep this data bank current, staff members of the Chemical Thermodynamic Data Center scan the primary literature and Chemical Abstracts each month, select articles, and abstract them. A typical data extract (on one measurement on one compound) is shown in Figure 5.

This index is now in two parts. Up to 1969 each information unit was written by hand on a $3 \times 5^{\prime \prime}$ card. Since then the abstracts have been keyboarded into a computer file and the hard copies of them have been produced by a complex report-writing program. This has reduced sharply the routine labor required of the data abstractors and at the same time has created an archival file of raw data.

The hand-written file covering chemical thermodynamics up to 1969 has been microfilmed and is being sold by the NBS Office of Standard Rererence Data. It contains images of 156,000 cards covering about 40,000 articles.

The computer based file, covering chemical thermodynamics since 1969, is available on site at NBS-Gaithersburg (as a card file) and has been distributed, in part, but only for special cooperative projects. Distribution of the entire file to the public is being considered in connection with the development of an on-line retrieval system. In the meantime, the limited version that appears in the Bulletin of Chemical Thermodynamics should serve as an effective guide to the literature [5].

The Bulletin is an annual current awareness service. It contains indexes to published thermodynamic and related studes on: organic substances and mixtures, 
inorganic substances, biological and macromolecular systems, and reports on current research throughout the world. It is issued under the auspices of IUPAC, edited by Prof. R.D. Freeman, OKlahoma State University, and published by Thermochemistry, Inc., Stillwater, Oklahoma. A typical section of a page from the Bulletin is shown in Figure 6.

3.2. Evaluation of Data The development of machine-readable evaluated chemical thermodynamic data is a result of the automation of parts of the final stage of the evaluation process in the Chemical Thermodynamics Data Center. "Machine readable" must be emphasized. Data banks similar to the ones to be described here existed in the pre-computer era. The evaluation process itself has two major parts:

a... evaluation of each set of measurements reported in an individual paper

- combining the acceptable measurements from the various sources to obtain selected, reliable values of properties.

The process has been discussed in detail elsewhere $[6,7,8]$. It is described briefly here starting with a brief discussion of the interconnected nature of thermodynamic data.

\subsubsection{The Thermochemical Data System}

A11 thermochemical measurements are relative, yielding changes in properties for processes. Thermochemical properties of a system also are functions only of the initial and final states and are independent of the path between the reactants and the products. These facts and what it is possible to measure control the structure of the thermochemical data system. There are two features that become apparent when a large number of such measurements are examined. First there is 
usually a very limited number of replicate measurements for any particular reaction. Intercomparison of many supposedly identical measurements is not a major part of the evaluation process.

Second, there often are several chemically distinct experiments or sets of experiments that lead from a particular reactant to a particular product. We call each of these distinct sets a "measurement pathway." The phenomenon is illustrated in Figure 7 for a few compounds of beryllium. It shows six pathways leading from Be to BeO. They involve measurements on six other compounds, each of which may be part of other networks. Because changes of thermochemical properties are independent of the path, all six paths from $\mathrm{Be}$ to $\mathrm{BeO}$ must lead to the same result, in the absence of experimental error.

The multiple measurement path phenomenon adds a dimension to the evaluation of chemical thermodynamic data that is absent from many other evaluation efforts: extensive quantitative cross checks. This multiple path phenomenon is a major feature. The extensive crosslinking in the thermochemistry of lithium compounds is displayed in Figure 8. The many possible intercomparisons make it possible to select a highly consistent data set.

The large data networks, such as Figure 8, are maps for linear algebra problems. Thermochemical measurements can be reduced, formally, to equations involving only the addition and subtraction of properties of compounds, and these appear only to the first power. An example is given in Figure 9 in which the measurement for a hydration process is decomposed into three terms, the enthalpies of formation of each substance from its chemical elements. Given an interconnected set of such equations, the enthalpies of formation can be solved for and then the "best values" for the processes reconstructed. For many years the solution of such networks has been done by hand, but now computer assisted solutions are becoming important. 
That such large thermochemical networks should be and are being solved using computer programs is due to the imagination and foresight of two groups of thermochemists. In the early 1960's Daniel Stu11, Dow Chemical Co. proposed a system in which all thermochemical measurements would be put into computer files and the entire set for all inorganic chemistry could be solved at one time. This concept was developed by A. N. Syverud [9]. Shortly thereafter J. Brian Pedley, University of Sussex, proposed a computerized system designed for rapid updating of tables and for coordinating the work of several groups of data evaluators [10]. He has used it to produce the CATCH Tables [11] and the Sussex - N.P.L. tables on organic compounds [12]. These computerized approaches have been merged by us, expanded in a cooperative program between NBS and the University of Sussex, and used on large networks.

\subsubsection{Treatment of Individual Papers}

The first step in solving a data network, by computer or not, is the preparation of the input data. This is the most difficult step. The data evaluator must verify the work reported in each paper, develop an exact statement describing the chemistry for each process, and reduce the measured value to a consistent set of conditions (temperature, pressure, atomic masses etc.). The overall accuracy must be estimated. All of these acts require the evaluator to have a broad knowledge of chemical thermodynamics. This preparation of the input is the most time consuming part of the entire evaluation process. It is over $80 \%$ of the work.

The results of each of these reanalyses can be summarized succinctly as shown in Figure 10: chemical reaction, property, value, uncertainty, reference and comments. They can be used directly as input to a machine solution of a thermochemical network problem. These reanalyses are also accumulated to form a catalog of evaluated thermochemical measurements that can be used to document the data evaluation. 
We expect to produce the documentation of the NBS Tables "Selected Values of Chemical Thermodynamic Properties" in the form of such catalogs, supplemented by commentary concerning special problems and tables of thermal functions used in the process. This is instant documentation in a detail that has not been practical previously.

One such catalog has been published. It covers the thermodynamics of compounds of thorium and is an experiment in highly structured, detailed documentation with the minimum of prose [13].

\subsubsection{Values for Chemical Thermodynamic Properties}

The second part of the evaluation process is the simultaneous solution of the network of thermodynamic equations to get the formation properties of the compounds. This is, in effect, the reconciliation of data from many laboratories. The network is an overdetermined set and has been solved by a robust procedure involving both least sums and least squares treatments. [6] Several iterations may be necessary because this is the first point in the process at which estimates of interlaboratory agreement and accuracy of methods can be made reliably.

The output from a network solution is a set of selected values for the $\Delta_{f} H^{\circ}, \Delta_{f} G^{\circ}$ and $S^{\circ} S$ of the compounds being studied. This solution has a property that is not well recognized. Because the measurements are all linked together, a change in one part of the network will cause changes in most of the $\Delta_{f} H^{\prime} s$, etc., while the best values for most of the individual processes will remain almost the same. This situation is the basis of pleas by evaluators that the user avoid mixing property values from several tables. It also explains why tables of thermochemical data are constructed to cover the full range of chemical compounds.

Because the totality of inorganic thermochemistry is still too large for one solution to be practical, a series of solutions has been made, usually for compounds of one element at a time, group by group across the periodic table from right to left. (As the results of each solution are entered into the data bank they become available as fixed data for later solutions. This keeps all solutions 
consistent with each other.) Solutions for compounds of eight elements: Th, $U, \mathrm{Li}, \mathrm{Na}, \mathrm{K}, \mathrm{Rb}, \mathrm{B}$, and $\mathrm{Cs}$, have been made by machine. Earlier solutions were made by hand, using a sequential technique.

The computer file of selected values is being used to produce the forthcoming NBS Tech. Note 270-8, the last in the series, and will be used to produce the combined volume for the entire series. With this computerized data bank it will be very easy to convert all values to SI units (from calories at 1 atmosphere to joules at $10^{5}$ pascal.) This data bank will also become part of the thermodynamics module of the Chemical Information System sponsored by NIH and EPA.

Let us return for a moment to the catalog of evaluated thermodynamic measurements. This catalog will outlive our "Selected Values" because new measurements will force modification of the selections. The catalog, supplemented with new data, and operated on by existing programs will permit an instant update. This would have been impractical using the older, manual, sequential methods. 4. Thermodynamic Data Banks at the Institute for High Temperatures

A very active thermodynamic data evaluation group at the Institute for High Temperatures of the USSR Academy of Sciences, Moscow (IVTAN), headed by L.V. Gurvich, publishes two sets of tables. They are "Thermodynamic Properties of Individual Substances" [14] and "Thermal Constants of Substances," [15] The former is analogous to the JANAF Thermochemical Tables [16] and the latter [15] is similar to NBS Technical Note 270, but also includes transition properties. In recent years the preparation of these volumes has been supported by a specialized data base management system that contains extensive data banks. Professor Gurvich has provided a description of this very attractive, flexible data system, which is given below in a slightly modified form.

The data bank on thermodynamic properties was created in the chemical thermodynamic department of the Institute of High Temperatures of the USSR Academy of Sciences (IVTAN). Unlike most other data banks, the IVTAN data bank does not accumulate the data recommended in various reference books. It contains 
or generates the thermodynamic properties data for a wide temperature range on the basis of critical analysis of all primary literature sources. This data bank is used in the conversational mode using the "Image" subsystem on an Hewlett-Packard 3000 computer system. It contains a number of disc files, one file for each compound. Data for different isomers and also gaseous and condensed phases of the same substance are stored in separate files.

The system consists of a set of programs and data bases. The data bases now include the following:

A) Auxiliary data such as fundamental constants, atomic masses etc.

B) Input data used for the calculation of thermal functions: These data include molecular constants for gases and values of heat capacity enthalpy change and phase transition characteristics for condensed substances. A11 the data are selected by expert analysis of the primary literature.

C) Experimental data on equilibrium constants of chemical reactions and vapor pressures of substances.

D) Intermediate constants obtained by statistical treatment and critical analysis of data (B) and (C), e.g. reduction of high temperature data.

E) Thermochemical constants (enthalpies of formation, enthalpies of sublimation, dissociation energies, ionization potentials, etc.) based on analysis of the primary literature and data from base (D).

F) Tables of thermodynamic properties, e.g. thermal functions, and related data for each substances.

The program set includes tens of programs and program modules providing for:

A) Treatment of primary experimental and theoretical data accumulated in bases $(B)$ and $(C)$. 
B) Calculation of thermal functions of substances in gaseous and condensed phases over a wide temperature interval using different approaches in order to get the best possible accuracy for each compound.

C) Estimation of uncertainties of the thermal functions taking into account the reliabilities of the selected values of constants and method of calculation.

D) Statistical treatment of primary experimental data contained in base $(C)$ using the calculated thermal functions.

E) Calculation of a consistent set of thermochemical constants for all compounds of a given element using data from base (E).

F) Calculation of the final table of thermodynamic properties for a given compound including equations fitting the tabulated thermal functions and equilibrium constants for the reaction of atomization (or evaporation).

G) Management of all parts of the data bank.

The data for more than 1000 substances have been accumulated in the IVTAN data bank up to the present. They cover all substances considered in the first three volumes of "Thermodynamic Properties of Individual Substances" and some substances from the last, fourth volume of this series.

In the continuation of this work, IVTAN plan to enlarge the list of elements and compounds, to introduce a bibliography and short descriptions, and to create a data base on direct results of experimental measurements of the enthalpy and free energy of chemical reactions. A number of new programs will be written also for more accurate calculation of the thermal functions of simple polyatomic gases, for obtaining an interconsistent set of thermochemical values for a given number of chemical substances from primary experimental data, etc. 
5. What of the Future? Where is chemical thermodynamic data evaluation going?

The problem for the future is the rapid updating and effective delivery of thermodynamic data. Already, the major compilations of evaluated data are aging. Suppose that a new set of tables of evaluated data is to be issued in 1985 . At least 25,000 new measurements will have to be considered and added to the catalogs. This is the bottleneck. The assessment of the individual paper has not been automated successfully although the process can be aided by calculational programs and graphical displays. Thus the answer must be to use all evaluative resources throughout the world in a cooperative program.

CODATA, the Committee on Data for Science and Technology, is developing such a program. The first phase is the highly successful international Task Group on Key Values for Thermodynamics which provided new recommendations for one hundred fifty substances that are base points for many thermochemical measurements. [17]. The second phase is a plan for a much larger multinational thermodynamic data gyaluation consortium that might produce the next round of thermochemical and thermophysical tables. This is being developed by the CODATA Task Group on Internationalization and Systematization of Thermodynamic Tables.

An example of what this might mean is shown in Figure 11. Here we have a series of independent groups (on the left) each contributing its output to an international system that would, in turn, serve the individual users.

The cooperative scheme would reduce the overlap in services that exists at present, and provide the users with a single set of recommendations and do this more rapidly. By splitting up the work, by exchange of data, and by common development of computer procedures the evaluation groups would greatly simplify their presents tasks.

If all this can be done, the future will indeed be bright for the user of thermodynamic data. 
1. Bichowsky, F.R., "Thermochemistry: Heats of Formation under Constant Pressure (Heats of Solution, Heats of Transition)" in Washburn, E. W., editor, International Critical Tables of Numerical Data, Physics, Chemistry and Technology" McGraw Hill Book Co., N.Y. 1929, vol. V pg 169-213.

2. Bichowsky, F.R. and Rossini, F.D., The Thermochemistry of the Chemical Substances, Reinhold Pub1. Co., N.Y., 1936, 460 pp.

3. Rossini, F.D., Wagman, D.D., Evans, W.H., Levine, S. and Jaffe, I., "Selected Values of Chemical Thermodynamic Properties", NBS Circular 500 (1952), 1268 pp.

4. Wagman, D.D., W.H. Evans, V.B. Parker, I. Halow, S.M. Bailey, and R.H. Schumm, "Selected Values of Chemical Thermodynamic Properties", U.S. Nat. Bur. Standards Tech. Note 270-3 (1968); idem, Tech. Note 270-4 (1969); Wagman, D.D., W.H. Evans, V.B. Parker, I Halow, S.M. Bailey, R.H. Schumm, and K.L. Churney, Tech. Note 270-5 (1971); Parker, V.B., D.D. Wagman, and W.H. Evans, Tech. Note 270-6 (1971); Schumm, R.H., D.D. Wagman, S.M. Bailey, W.H. Evans, V.B. Parker, Tech. Note 270-7 (1973); Wagman, D.D., W.H. Evans, V.B. Parker, R.H. Schumm and R.L. Nuttall, Tech. Note 270- 8 (1981), U.S. Govt. Printing Office, Washington, D.C.

5. Freeman, R.D., editor, Bul1. Chem. Thermodynamics (Thermochemistry, Inc. Stillwater, Oklahoma) vol. 22 (1979).

6. Garvin, D., V.B. Parker, D.D. Wagman and W.H. Evans, "A Combined Least Sums and Least Squares Approach to the Solution of Thermodynamic Data Networks" in B. Dreyfus, editor, Proc. Fifth Biennial Int. CODATA Conf., Pergamon, N.Y. 1977, pg 567. 
7. Wagman, D.C., D. Garvin, V.B. Parker, W.H. Evans, J.B. Pedley and P.M. Burkinshaw, "Handling and Evaluation of Large Networks of Thermochemical Data", Seventh Int. CODATA Conf., Kyoto, Japan, Oct. 8-11, 1980.

8. Wagman, D.D., D. Garvin, V.B. Parker, R.H. Schumm and J.B. Pedley. "New development in the evaluation of thermochemical data". In National Measurement Laboratory 1979 Technical Highlights. U.S. Nat. Bur. Stand., Spec. Publ. 572, U.S. Govt. Printing Office, Washington, D.C. 91980), pp 53-55.

9. Syverud, A.N. and Klein, M. (Periodic Reports on USDC-NBS Contract CST 1165), Dow Chemical Co., Midland, Mich., 1964-65.

10. Guest, M.F., Pedley, J.B. and Horn, M., "Analysis by computer of thermochemical data on boron compounds", J. Chem. Thermodynamics, (1969), 1, 345 .

11. Pedley, J.B. (ed.), Computer Analysis of Thermochemical Data (CATCH Tables), University of Sussex, Brighton. Data selectors and tables issued: Cox, J.G., "Halogen Compounds" (1972); Pilcher, G., "Nitrogen Compounds" (1972); Pedley, J.B. and Iseard, B.S., "Silicon Compounds" (1972); Head, A.J., "Phosphorus Compounds" (1972); Barnes, D.S., "Cr, Mo and W Compounds" (1974).

12. Pedley, J.B., and J. Rytance, Sussex-N.P.L. Computer Analyzed Thermochemical Data: Organic and Organometallic Compounds." University of Sussex, Brighton, England (1977).

13. Wagman, D.D., R.H. Schumm, and V.B. Parker. A Computer-Assisted Evaluation of the Thermochemical Data of the Compounds of Thorium. NBSIR 77-1300. U.S. Nat. Bur. Standards, Washington, D.C. (1977). 
14. Glushko, V.P., L.V. Gurvich, G.A. Bergman, I.V. Veits, V.A. Medvedev, G.A. Khachkuruzov, and V.S. Yungman, eds. "Thermodinamicheskie Svoistva Individual 'nykh Veschestv", vol. 1, parts 1 and 2 (1978), vol. 2, parts 1 and 2 (1979), Izdatel'stvo "Nauka" Moscow.

15. Glushko, V.P., V.A. Medvedev, G.A. Bergman, L.V. Gurvich, V.S. Yungman, A.F. Vorob'ev, V.P. Kolesov, L.A. Reznitskii, G.L. Gal'chenko, and for various volumes, V.V. Mikhilov, M. Kh. Karapet'yants, V.P. Vasilev, V.N. Kostryukov, N.T. Ioffe, G.G. Malenkov, N.L. Smirnova, V.F. Baibuz, V.I. Alekseev, I.L. Khodakovskii, K.B. Yatsimirskii, and B.P. Biryukov, editors, "Termicheskii Konstanty Veshchestv", Vol. 1 (1965), Vol. 2 (1966), Vol. 3 (1968), Vol. 4, part 1 (1970), part 2 (1971), vol. 5 (1971), Vol. 6, part 1 (1972), part 2 (1973), Vol. 7 in 2 parts (1974), vol. 8 in 2 parts (1978), Vol. 9 (1979); Viniti, Moscow.

16. Stul1, D.R. and H. Prophet, JANAF Thermochemical Tables, 2d Ed., Nat. Stand. Ref. Data Ser., Nat. Bur. Stand. (U.S.), (1971) 37. Chase, M.W., J.L. Curnutt, A.T. Hu, H. Prophet, A.N. Syverud and L.C. Walker, - 1974 Supplement, J. Phys. Chem. Ref. Data (1974) 3, 311-480. Chase, M.W., J.L. Curnutt, H. Prophet, R.A. McDonald, A.N. Syverud, - 1975 Supplement, J. Phys. Chem. Ref. Data (1975) 4 , 1-175.

Chase, M.W., Curnutt, J.L., R.A. McDonald, A.N. Syverud, J. Phys. Chem. Ref. Data (1978) 7, 793-940.

17. CODATA Task Group on Key Values for Thermodynamics J.D. Cox. Chairman (1978). "CODATA Recommended Key Values for Thermodynamics 1977." CODATA Bulletin 28. CODATA, Paris, Idem (1980). "Tentative Set of Key Values for Thermodynamics. Part VIII". CODATA Special Report No. 8. CODATA, Paris. 
Figure 1. A thermodynamic cycle involving a chemical reaction at two temperatures.

Figure 2. Sample entries from the table on compounds of sodium from NBS Tech. Note 270-8. The highlighted items are new material, showing expansion from NBS Circular 500. All properties values (highlighted or not) are the result of new evaluations.

Figure 3. Chemical thermodynamic properties included in the International Critical Tables, Bichowsky and Rossini, NBS Circular 500 and NBS Tech. Note 270.

Figure 4. Growth of compiled chemical thermodynamic data over a fifty year period.

Figure 5. Extract of Data. The contents summarize one set of measurements of a property of a single compound. This is the useful information unit in chemical thermodynamics.

Figure 6. Section of a page from the Bulletin of Chemical Thermodynamics showing the substance, property measured (two letter code) and reference.

Figure 7. A Thermochemical network showing the measurement paths leading from elemental beryllium to beryllium oxide.

Figure 8. Lithium Thermochemical Network. Each node (box) is a compound and each line is a measurement. The common starting point at the left is $L i(c)$ and the top two compounds in the next column are $\mathrm{Li}(\mathrm{g})$ and $\mathrm{Li}^{+}$(aq, std. state). Rectangles are enthalpies, diamonds are Gibbs energies and hexagons are entropies.

Figure 9. Thermochemical process showing relationship of the measured enthalpy to enthalpies of formation.

Figure 10.Reaction Catalog. Examples of the stylized summary of evaluated data. The form actually used is machine readable.

Figure 11. International Cooperation in Thermodynamic Data Evaluation. A possible organization of a consortium. 


$$
\begin{aligned}
& \mathrm{A}+\mathrm{B} \stackrel{\mathrm{T}_{2}}{\longrightarrow} \mathrm{C} \\
& \uparrow \uparrow \text { THERMOPHYSICAL } \\
& \mathrm{H}_{2}-\mathrm{H}_{1} \\
& \left(G_{2}-H_{1}\right) / T_{2} \\
& \mathrm{~A}+\mathrm{B} \longrightarrow \mathrm{C}
\end{aligned}
$$

THERMOCHEMICAL

$\Delta H, \Delta G, \Delta S$

FIGURE I 


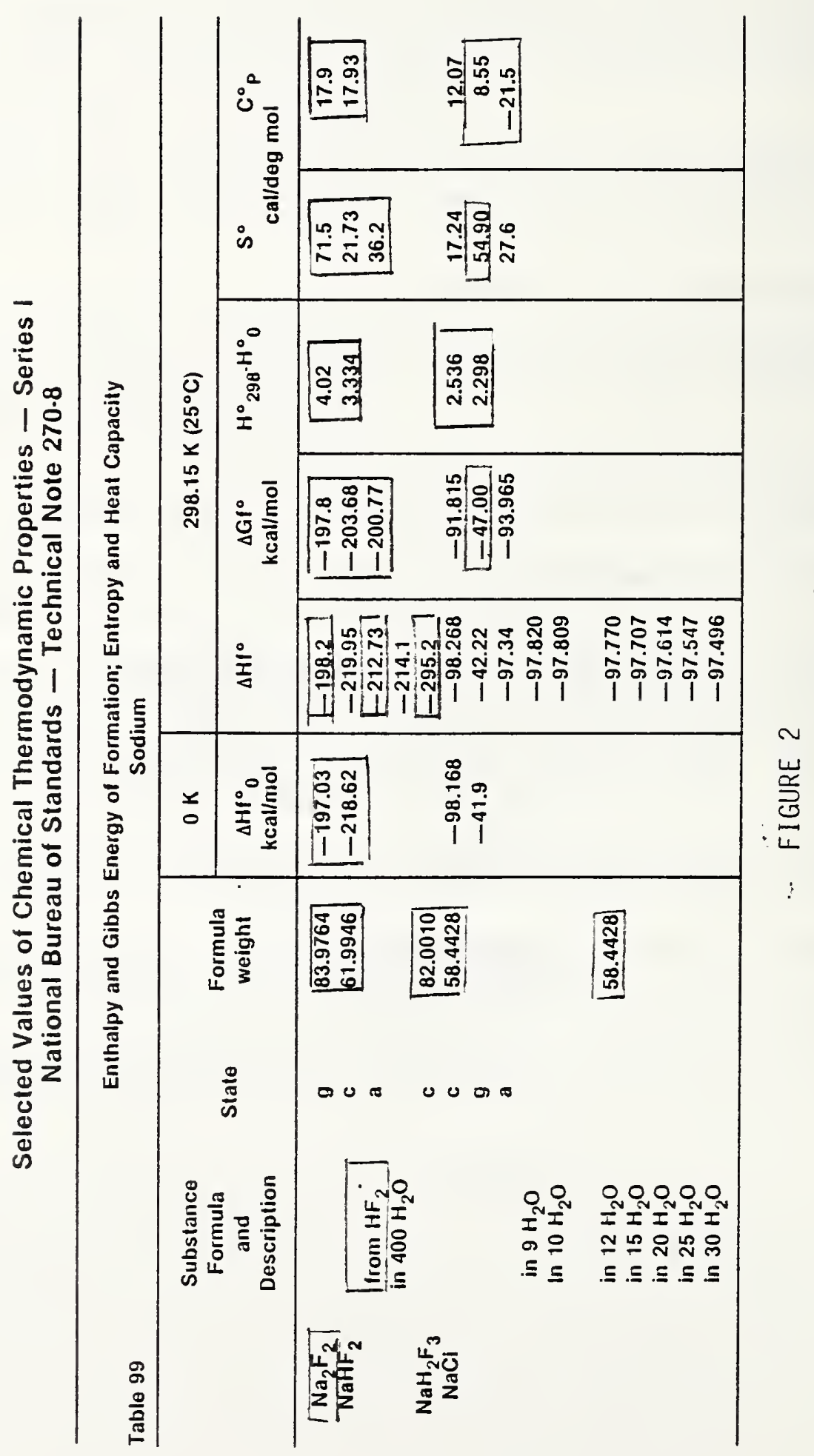


ICT B\&R C500 TN 270

$\Delta_{F} H$

$X$

$X \quad X$

$\Delta_{F} G$

$x \quad x$

$S$

$\Delta_{F} H_{0}$

$\begin{array}{ll}x & x \\ X & X\end{array}$

$\mathrm{H}-\mathrm{H}_{\mathrm{O}}$

$C_{p}$

$x$
$x \quad x$

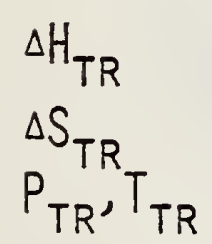

$x \quad x \quad x$

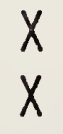

FIGURE 3 


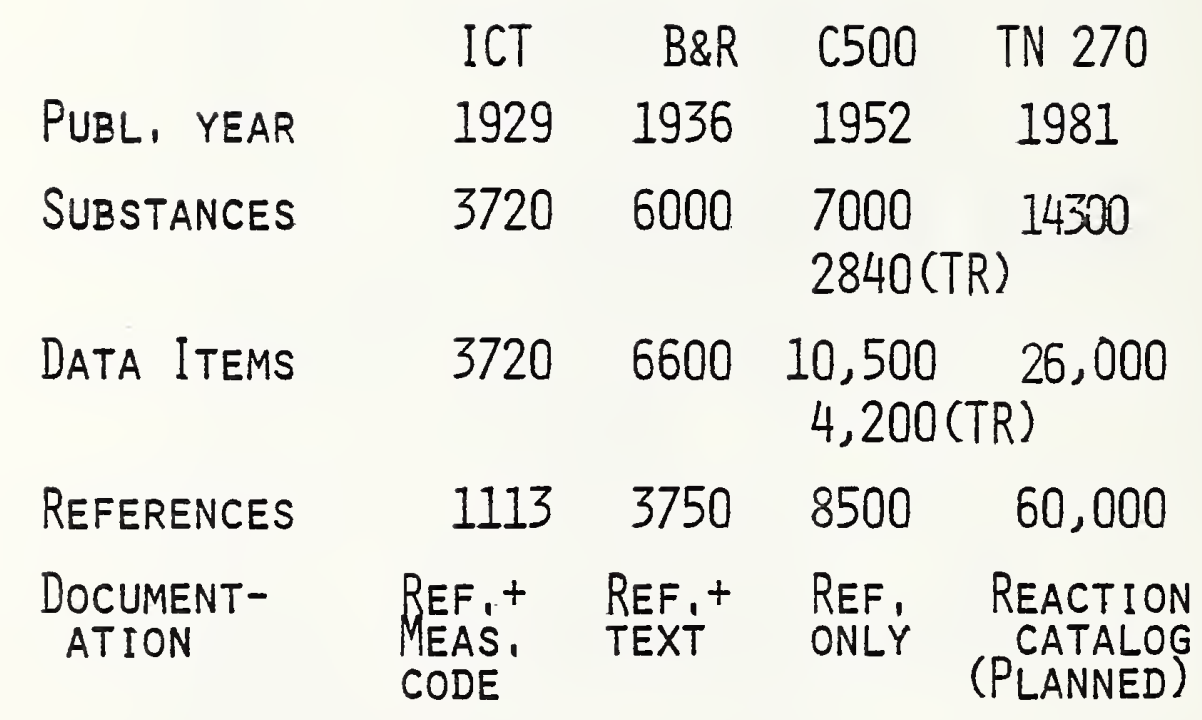

FIGURE 4 
$8 \mathrm{aCl}_{2}\left(\mathrm{aq}, 800 \mathrm{H}_{2} \mathrm{O}\right)$

Sobol, L.G., and Selivanonva, N.M., F Zhur. Fiz. Khim. $43,2937-2938(1969)$

Meas. heat of reaction of $\mathrm{NaHSO}_{4}$ and $\mathrm{NaHSO}_{4} \cdot \mathrm{H}_{2} \mathrm{O}$ with

$8 a C l_{2}(a q)$, plus heats of solution, at $25 \mathrm{C}$ in isothermal-

jacket calorimeter.

$\mathrm{BaCl}_{2}\left(80 \mathrm{OH}_{2} \mathrm{O}\right)+\mathrm{NaHSO}_{4} \cdot \mathrm{H}_{2} \mathrm{O}(\mathrm{c})=8 \mathrm{aSO}_{4}(\mathrm{c})$

$+\mathrm{NaCl}\left(800 \mathrm{H}_{2} \mathrm{O}\right)+\mathrm{HC}\left(\left(800 \mathrm{H}_{2} \mathrm{O}\right)+\mathrm{H}_{2} \mathrm{O}(\mathrm{liq})\right.$

$\Delta H=-6.7 \pm 0.10 \mathrm{kcal} / \mathrm{mol}$

$\mathrm{BaCl}$

691442

\section{FIGURE 5}

47. OSMIUM Os

$\mathrm{O}_{5} / \mathrm{Zrc} / \mathrm{liq}$
$\mathrm{OsO}_{1}(\mathrm{~g})$
$\mathrm{OsO}_{1}(\mathrm{~g})$
$\mathrm{O}_{5} \mathrm{O}_{1} \mathrm{~F}(\mathrm{~g})$ $\begin{array}{ll}\text { Px } & 5623-79 \\ \text { Md } & 5209-79 \\ \text { Md } & 5672-79\end{array}$

Md $\$ 672-79$

48. MaNGANESE Mn

\begin{tabular}{|c|c|c|}
\hline $\operatorname{Mn}(a q)$ & $P_{x}$ & $6811-79$ \\
\hline $\mathrm{Mn}(c)+\mathrm{FeS}_{\mathrm{e}}(\mathrm{c})=\mathrm{MnS}(\mathrm{c})+\mathrm{Fe}_{\mathrm{e}}(\mathrm{c})$ & $\mathrm{Kk}$ & $6525-79$ \\
\hline $\mathrm{Mn}\left(\mathrm{l}_{\mathrm{q}}\right)-\mathrm{H}_{2}(\mathrm{~g})$ & $P_{x}$ & $6580-79$ \\
\hline $\mathrm{Mn}_{n}-\mathrm{F}_{e}-\mathrm{O}(\mathrm{liq})$ & Px & $6672-79$ \\
\hline $\mathrm{Mn} / \mathrm{O} / \mathrm{S} / \mathrm{Fe} / \mathrm{Ti}$ & $D_{m} P_{x}$ & AUSOOIK \\
\hline $\mathrm{Mn} / \mathrm{D}$ : & $\mathrm{Hm}$ & GFR023P \\
\hline $\mathrm{Mn} / \mathrm{D}_{2}$ & Pr & GFR023P \\
\hline
\end{tabular}




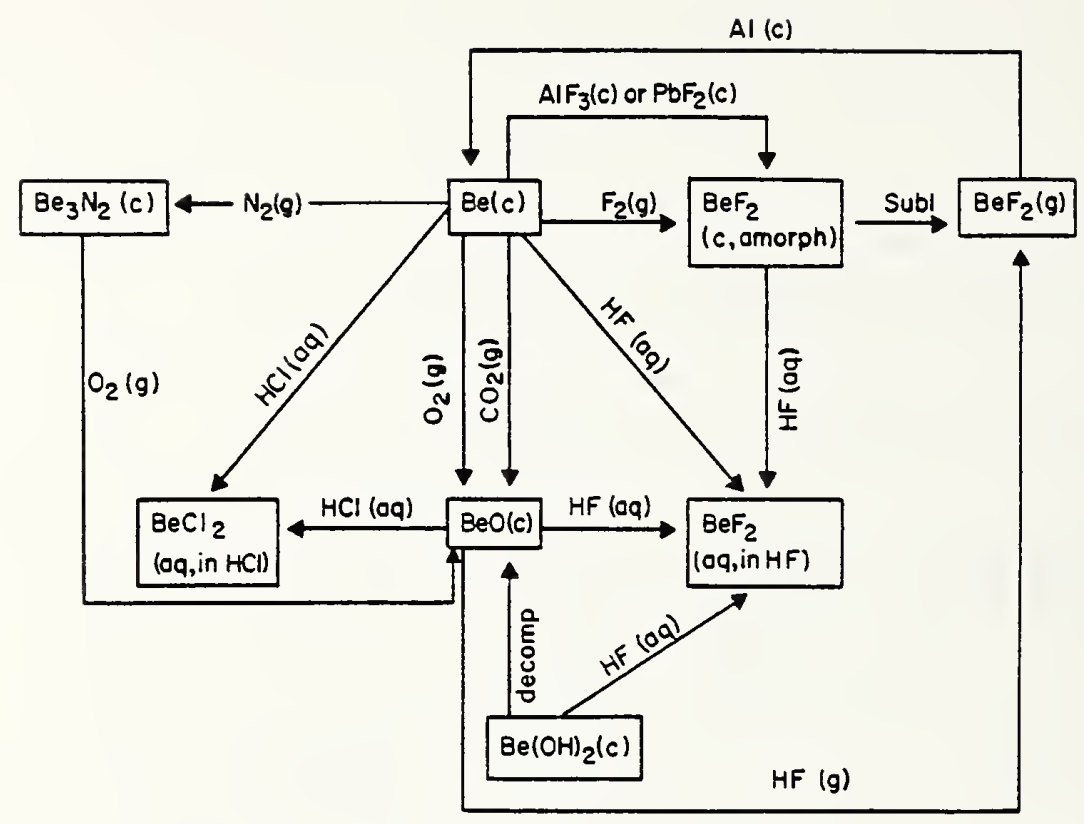

FIGURE 7

See next page for Figure 8.

$$
\begin{aligned}
\mathrm{NaBr}(\mathrm{C}) & +2 \mathrm{H}_{2} \mathrm{O}(\mathrm{C})=\mathrm{NaBr} \cdot 2 \mathrm{H}_{2} \mathrm{O}(\mathrm{c}) \\
\Delta H & =-19.24 \pm 0.05 \mathrm{~kJ} / \mathrm{mol} \\
& =\Delta_{f} \mathrm{H}\left(\mathrm{NaBr} \cdot 2 \mathrm{H}_{2} \mathrm{O}\right)-\Delta_{f} \mathrm{H}(\mathrm{NaBr})-2 \Delta_{f} \mathrm{H}\left(\mathrm{H}_{2} \mathrm{O}\right) \\
Y \pm U & =(-19.24 \pm 0.05) \mathrm{kJ} / \mathrm{mol}=x_{3}-x_{1}-2 x_{2}
\end{aligned}
$$

FIGURE 9 


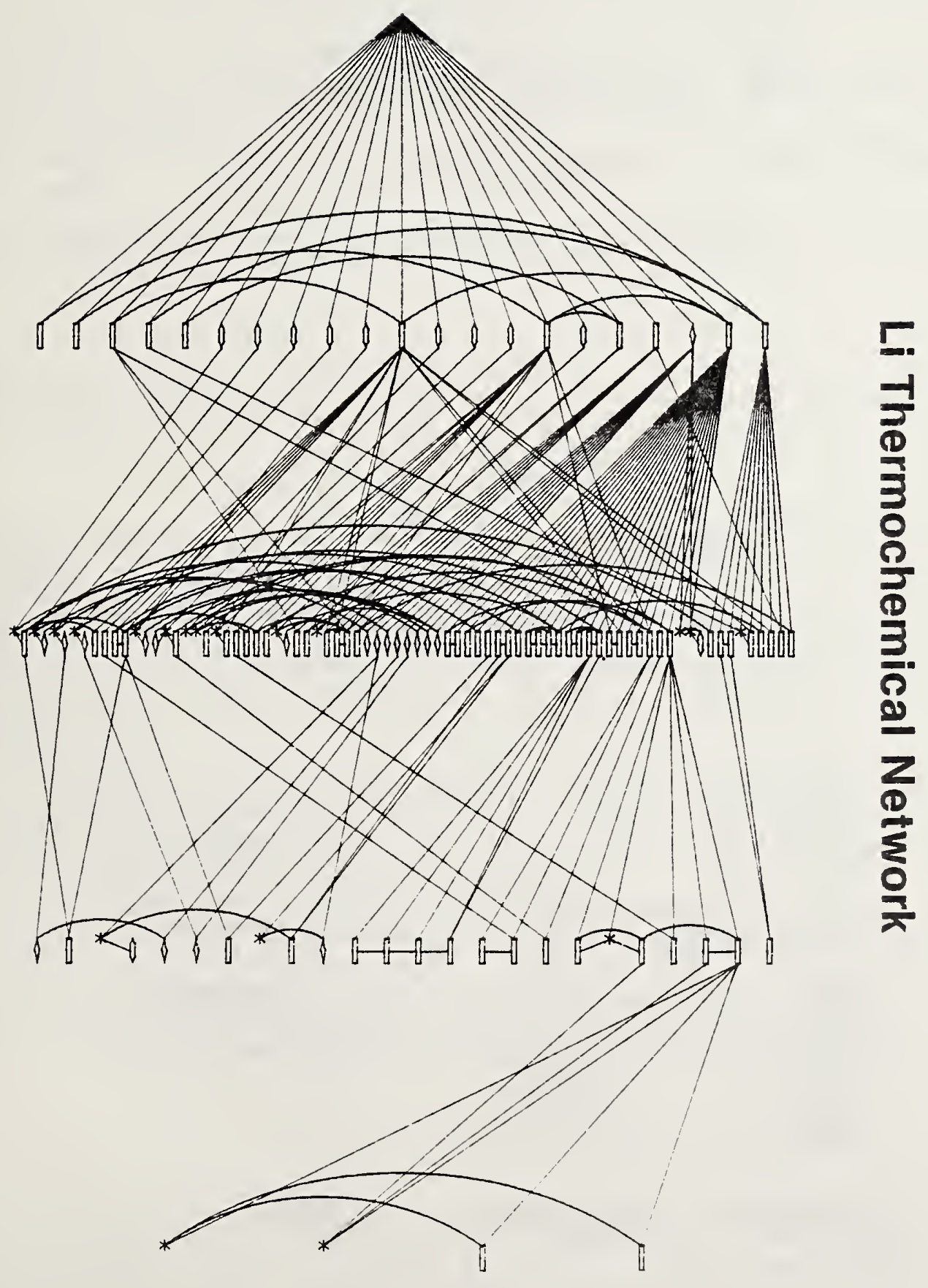


REFERENCE: 6GARO/AUS

- PROPERTY MEASUREO: H (OR G OR S); UNIT: C (OR J OR V)

OBSERVEO VALUE +- UNCERT.: $37.0+-4.5$

REACTION: TH'3N4(C) $=3 \mathrm{TH}^{\prime} \mathrm{N}(\mathrm{C})+0.5 \mathrm{~N} 2(\mathrm{GS})$

COMMENT: AUTHORS'2NO-LAW VALUE 36.35 AT APPROX. $1923 \mathrm{x}$

AOJ'O BY 0.65 USING ESTO. CP $\left(T_{H} 3 \mathrm{~J}_{4}\right)=39.33+$

$0.00624 T-533000 / T 2$.

BIBLIOGRAPHY: ARONSON, S.; AUSKERN, A.B.; J. PHYS.CHEM. $70,3937(1966)$.

FIGURE 10

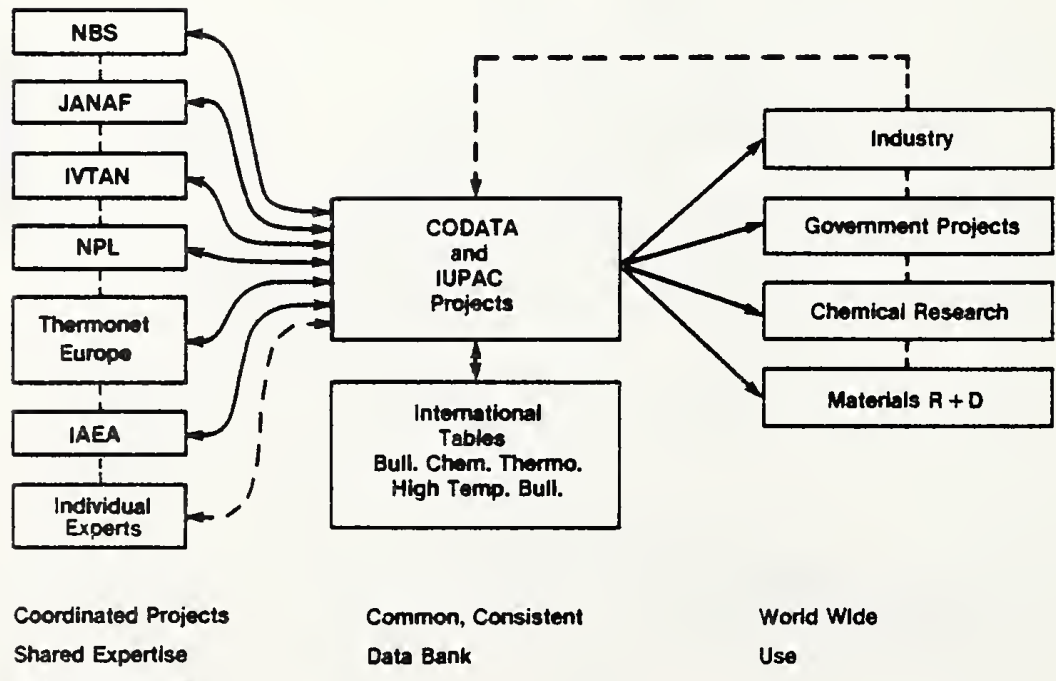

Shared Work Laed 
NBS-114A (REV. 2.80)

U.S. DEPT. OF COMM.

1. PUBLICATION OR REPORT NO.

BIBLIOGRAPHIC DATA

SHEET (See instructions)

NBSIR 81-2341

2. Performing Organ. Report Nof 3. Publication Date

August 1981

4. TITLE AND SUBTITLE

Chemical Thermodynamic Data Banks

5. AUTHOR(S)

David Garvin, Vivian B. Parker, Donald D. Wagman

6. PERFORMING ORGANIZATION (If joint or other thon NBS, see instructions)

NATIONAL BUREAU OF STANDARDS

DEPARTMENT OF COMMERCE

WASHINGTON, D.C. 20234

9. SPONSORING ORGANIZATION NAME AND COMPLETE ADDRESS (Street, City, Stote, ZIP)

7. Contract/Grant No.

8. Type of Report \& Period Covered

10. SUPPLEMENTARY NOTES

$\square$ Document describes a computer program; SF-185, FIPS Software Summary, is attached.

11. ABSTRACT (A 200-word or less factual summary of most significant information. If document includes a significant bibliography or literature survey. mention it here)

A substantial critical evaluation of chemical thermodynamic measurements on inorganic and $C_{1}-C_{2}$ organic compounds has recently been completed. This provides selected values for some 14300 substances, based on a collection of 250,000 measurements This work is placed in a historical context of three earlier comprehensive evaluations of thermochemical data.

During the course of this work data banks of several types have been developed: bibliography, extracted unevaluated data, evaluated measurements (catalogs of reaction\$) and selected chemical thermodynamic properties for individual substances. The design, structure and use of those data banks are described.

The course of modern data evaluation, based on these files, is discussed briefly in terms of tests for inter-measurement consistency and autmoated solutions of large networks of data.

A complementary thermodynamic data system developed at the Institute for High Temperatures, Moscow, USSR is described briefly. Proposed international activities are outlined.

12. KEY WORDS (Six to twelve entries; alphabetical order; capitalize only proper names; and separate key words by semicolon s) chemical thermodynamics; data evaluation; data banks; inforamtion systems; networks of data; standard reference data; thermochemistry.

13. AVAILABILITY

X Unlimited

$\square$ For Official Distribution. Do Not Release to NTIS

$\square$ Order From Superintendent of Documents, U.S. Government Printing Office, Washington, D.C. 20402.

14. NO. OF

PRINTED PAGES

X] Order From National Technical Information Service (NTIS). Springfield, VA. 22161 

